\title{
Trapped in the Cycle of Violence: A Phenomenological Study Describing the Stages of Coping with Domestic Violence
}

\author{
Mashudu Davhana-Maselesele \\ Faculty of Agriculture; Science and Technology, North West University (Mafikeng Campus) \\ Mmabatho, South Africa 2735 \\ E-mail: Mashudu.maselesele@nwu.ac.za
}

KEYWORDS Abuse. Acceptance. Anger. Apathy. Denial. Retaliation. Re-discovery. Self Blame. Uncertainty

\begin{abstract}
One of the most persistent maladies of domestic violence is that its victims are always blamed, even by trusted sources of social capital support, for staying in an abusive relationship. Questions as to why the woman victim does not leave are always asked, and most often women are blamed for continuing to stay. This brings to the fore the question of their coping strategies as it relates to abusive partners. This paper specifically examines how women go through and cope with domestic violence. A qualitative descriptive, exploratory and contextual study was conducted with women who are victims of domestic violence. Phenomenological interviews were conducted with women who volunteered to participate in the study. A sample was purposively selected of women who were staying with their abusive partners, tolerating abusive relationship for a period of more than 20 years. Ethical measures were adhered to bearing in mind the sensitivity of this research. Findings revealed six stages of coping which abused women go through as they ride on what was become known as the Walkers' Cycle of Violence. It is important to understand the world that a victim of domestic violence lives in, and the paces they take, so as to be able to understand her and be able to provide the necessary support without being judgemental. Ultimately, empowerment strategies, as opposed to run-of-the-mill 'holistic approaches', are recommended for redeeming the victim's lot and redirecting the survivor's coping skills beyond institutional intervention.
\end{abstract}

\section{INTRODUCTION}

Domestic Violence has been declared a Public health problem with devastating health consequences by the WHO (2003). Research conducted by the National Center for Injury Prevention and Control (2003) revealed that the rate of domestic violence was standing at 5.3 million. The rate of domestic violence is further perpetuated by the many factors that contribute to silence and thus continual endurance of pain and suffering; namely:

- Fear of further assaults;

- Fear of intimidation and lack of protection and support;

- Hope that things will change for the better.

Societal views about domestic violence play a major role in victims breaking the silence about abuse. A judgmental society will always make victims averse to report as the tendency is more of victim blaming.

A general lack of critical enabling facilities, such as crisis intervention centres or hotlines, shelters, advocacy agencies and proper telephone lines, hampers the victims of domestic violence who wish to seek help. The absence of these facilities, especially in rural areas, makes it difficult for victims to seek help and protection. Whilst on the other hand there are those victims who would not seek neither help nor report incidences of physical assault by their intimate partners as they attribute violence as their own fault.

According to Ferraro and Johnson (1983) in (Kearney 2001) women had six reasons for staying in an abusive relationships; namely:

- 'the salvation ethic - the need to care for the abuser;

- a commitment to the higher loyalities of religion or tradition;

- denial that the abuse is controllable,

- denial that their injuries were real;

- that they were blameless victims;

- inability to see practical or emotional alternatives'.

Walker's cycle of abuse (Gerhard 2000) describes the pattern of violence, which is composed of three phases. During the first phase referred to as tension building where tension builds up on the abuser until it reaches a stage of conflict when the abuser becomes violent and assaults the wife (phase two - acute battering). After the violent episodes the abuser feels ashamed and apologizes. He promises that he will never do it again (phase three-honeymoon). The honeymoon phase is characterized by presents given to the victim.

Phase Three wears off and the woman is left with a cycle of tension-building which results in a 
syndrome of increasing medical and emotional problems such as depression, anxiety, substance abuse and other signs of post-traumatic stress (Gerard 2000). It is very difficult to identify victims of domestic violence because the person becomes isolated and feels powerless (Gerard 2000).

The Women's Rural Advocacy Programs (1996) indicates that women ride in an abusive cycle around with their abusers. Abusive episodes would vary. At a certain time tension and acute battering take place and at other times intense peace prevails. Walker's cycle of abuse (Walker 1984) described how a victim gets trapped in an abusive relationship. The three dynamics of love, hope and fear keep the cycle of domestic violence in motion (Vetcamp and Miller 1990) and this compels a victim to endure an abusive relationship. As the batterer apologizes for his behavior, the victim hopes that things will change and that the abuse will not go any further. The victim's love for the partner compels her to stay in this relationship as she thinks of the good things which the perpetrator does for his family. Fear urges the victim to endure the suffering due to threats that make her feel intimidated. During this stage the batterer makes the victim feel guilty for any action taken and she might even drop legal charges.

Crawford (2001) states that when a person has become addicted to violent behaviour, violence becomes the norm for the day-to-day existence of the whole family. All family members sink into an angry and depressed state of resignation. On the other hand, an angry family produces an angry and violent society.

As the cycle progresses this also has an impact on the life of the victim and after continual abusive episodes the victim undergoes the stages.

In this article attention is given to stages which abused women underwent whilst riding on the cycle of Love, Hope and Fear as described by Walker (1984).

Walker's cycle attempted to provide answers to questions such as "why doesn't she leave?" This study further interrogated this question by interviewing women who have been staying with their abusive intimate partners for a period which ranged from 8 to 20 years.

\section{METHODOLOGY}

A phenomenological, qualitative, descriptive and contextual study was conducted with 18 women sharing their lived experiences of living with abusive intimate partners. Participants were selected on the basis of the following set criteria:

- Victims who were experiencing domestic violence and have agreed to participate in the study.

- Victims who stayed in an abusive relationship, married or not, or should have survived domestic violence.

\section{Data Collection}

In depth phenomenological interviews (Kvale1983) were conducted with the aim of exploring and describing the lived experiences of the victims of domestic violence. One central question was asked as follows: "Please tell me how you are copying in staying with an abusive partner."

The purpose of using phenomenological interviews for victims is to encourage them to speak openly, without any threats of fear, while observing non-verbal cues of the participants. Interviews were tape-recorded and all observations made were recorded as field notes.

A private place was sought to encourage free discussion without any threats, be they perceived or real.

\section{Measures to Ensure Trustworthiness}

Guba's model (Lincoln and Guba 1985) of trustworthiness has been applied. Credibility was ensured by continual interaction with abused women. The researcher spent time with victims of domestic violence. Follow-up interviews with participants were conducted and member-checking was done to verify the findings. Triangulation of data collection methods was done as field notes were also used to collect data. Transferability was enhanced by purposive sampling of participants who have been abused. Detailed and dense description of results as well as literature control were done to support the findings. Confirmability was ensured through the use of an independent coder who analyzed the data independently and a consensus discussion was held to agree on adopted themes and categories.

\section{Ethical Measures}

Guidelines as laid down by the Democratic Nurses Association of South Africa (1998) were adhered to. Permission to conduct the study was sought from the Department of Health Research 
Ethics Committee. Voluntary participation and written consent were sought from all participants and information about the research was expressly given. Participants were informed about the right to withdraw from the research at any time. The participants were also told that if they feel that there are issues which should not be recorded, then the audiotape will be switched off.

The researcher ensured that all collected information was stored and used in such a manner that confidentiality, anonymity and privacy of all participants were maintained at all costs, bearing in mind the sensitivity of the research. Referrals were made to relevant people such as social workers/ psychologist when necessary. When victims talk about their lived experiences in domestic violence, it was therapeutic to them as it was also a way relieving anger.

\section{RESULTS AND DISCUSSION}

Participants expressed how they endured the pain and suffering in their marital journey with their loved partners. Table 1 provides demographic characteristics of participants. Despite all physical assaults 96 percent of participants were still staying with their abusive partners.

Table 1: Demographic characteristics

\begin{tabular}{llr}
\hline $\begin{array}{l}\text { Demographic } \\
\text { characteristics } \%\end{array}$ & $\begin{array}{r}\text { Physical } \\
\text { assault } \\
n=18\end{array}$ \\
\hline Ethnicity & Venda & $100 \%$ \\
$(\mathrm{~N}=18)$ & Shangaan/Tsonga & $0 \%$ \\
Education & None & $30 \%$ \\
$(\mathrm{~N}=18)$ & Matric & $50 \%$ \\
& Basic degree & $20 \%$ \\
Employment & Working full time & $20 \%$ \\
$(\mathrm{~N}=18)$ & Housewife & $20 \%$ \\
& Attending school & $27 \%$ \\
Marital status & Unemployed & $33 \%$ \\
$(\mathrm{~N}=18)$ & Married & $96 \%$ \\
& Separated & $4 \%$ \\
& Widowed & $0 \%$ \\
Status of current & Never married & 0 \\
relationship & Cohabiting & 0 \\
& Hive with partner & $96 \%$ \\
& Dave regular partner & 0 \\
& Date occasionally & $4 \%$ \\
& No relationship in & \\
\hline
\end{tabular}

As a result of these women lived stories that they shared in their abusive relationship, stages of coping with their abusers were developed and will be discussed in the paragraphs that follows:

\section{Stages of Coping within Violent Abusive Relationship}

\section{Self-blame /Denial}

During interviews women expressed how they try to cope with their abusers by trying to understand why this was happening to them. This stage occurs at the initial stages of violence. As a result some expressions/statements revealed denial as a coping mechanism as follows:

"My husband is experiencing serious pressure, I shouldn't have talked to him, it was too soon."

"His girlfriend/relative is the one who is influencing him to abuse me."

"He has a financial problem; at least I should give him my salary so that he will pay for his extra expenses."

"At least he loves me, he did not mean to hurt me."

In trying to understand and to cope with the abuser she finds excuses for her abuse. It hurts the victim to realize that the man she thought loved her has turned into a monster. She finds it very difficult to accept that her husband is abusing her. The victim blames herself that she is responsible for the abuse and she is of the opinion that she deserves to be treated in that way. She denies that her partner is responsible for his actions. Bochonok (2000) states that denial is the greatest barrier for a victim to get help.

Other studies Pilowsky 1993 (in Kearney 2001) confirmed this stage through a statement from an abused woman who was attacked for the first time as follows: 'I just could not believe he had punched me'

Lempert 1996 (in Kearney 2001) revealed denial during the first violence attack as follows: I didn't really consider that it was his fault, and I wasn't the type of person ...you know (to) just walk out and leave... I'd rather do a lot of things to sort out the problem and work it out ... The husband comes first, to please the man that you're married to 'cause you committed yourself.

In addition, Turner (in Birken 2002) states that women blame themselves for their abuse and this makes it very difficult for them to leave their abusive relationships. Walker (1984) states that women accept responsibility for the perpetrators' actions. This usually occurs when she does not want to report her partner to the police. Depending upon the situation she can even blame herself for the situation. This was supported by the following statements during the interviews with abused women: 
During this stage she tries by all means to satisfy her husband and to calm him down. Walker (1984) indicates that a victim tries not to respond to his hostile actions and uses anger reduction techniques to calm his "nerves" during the tensionbuilding phase. Pierson (2001) on the other hand argues that the victim "walks around on eggshells" so as not to "set off" her partner. This makes the victims to accept that she is responsible for her own abuse. Olson (2002) indicates that a woman learns to read her husband's moods and avoids confrontation until the anger has subsided. When she realises that all her efforts are failing, she enters into the second stage of apathy.

\section{Apathy}

When abuse becomes a culture the victim gets confused and does not know how she should respond to this. At this stage the woman does not know what to do. She feels very helpless. When she realizes that she cannot control his anger she eventually withdraws from her abuser. When the abuser realizes that the victim has withdrawn, he becomes more aggressive. This stage is evidenced by responses of women who indicated the following:

"My husband assaulted me for not asking him why he did not come home. This means you were happy when I was not around. You were happy that I was not around and you thought I would be dead."

"I did not ask for his money because I did not want to be beaten."

"I do not know what to do, everything that I do for this man is never right, there is nothing I could do to please him, I can't even iron nor cook. He always tells me that I am a whore, ugly and shapeless."

Kearney (2001) describes this stage of enduring as shrinking of self which involved restraining one's emotional responses in order to avoid flare-ups, perform unwanted tasks or accept undeserved punishment.

Walker (1984) refers to this as a situation of "learned helplessness". The woman alienates herself from the abuser. Olson (2002) cites that a woman withdraws and does not make any decisions to ensure peace. Withdrawal from any decisionmaking also contributes to tension building and poor communication in the family. Peterson et al. (1993) argue that victims of domestic violence experience passivity rather than learned helplessness as a way of protecting themselves from being assaulted.

\section{Uncertainty}

During this stage the victim is afraid to take a decision regarding leaving the abuser. As the abuser has succeeded in destroying her self-concept and confidence the victim therefore cannot make decisions due to fear of the unknown. This stage often occurs immediately after an acute battering incident, when the woman has sustained injuries or called the police to seek protection. During this stage the abuser has to face the consequences of his actions whilst on the other hand the woman would start asking herself a long list of questions. This is also because the woman is in search of her identity.

This was evidenced by the following questions which participants raised during the interviews:

How do I face the future without him?

What will I do without him?

What will happen to my kids?

What will people say when they found out that I have reported my husband?

Some women expressed uncertainty as follows:

"May be it is better to stay where you are than to leave."

"The devil that I know is better than the one I do not know."

"Part of me says I should report him, part of me says I still love him so much that I cannot do that."

After all these statements the woman usually cancels the case if she has reported the perpetrator to the police. The decision to cancel the case or to go back to her spouse (if she had fled) is influenced by the apologies of the abuser to his partner. According to Walker's Cycle Theory of Violence the honeymoon phase (Gerhard 2000) encourages the victim to make decisions in favor of her abuser.

Kearney (2001) in support for uncetainity indicated that some women found their abusive relationships less frightening than the outside world and returned to their abusers.

\section{Acceptance}

During this stage the victim accepts that there is nothing she can do about the abuse. She accepts that she was just unfortunate to marry an abusive partner but she is prepared to endure the relationship. This was evidenced by the following statements:

"I have made a commitment to this marriage that until death do us part, therefore I will not go away, he will have to kill me if he wants". 
When a victim is going through this stage, it is very difficult to convince this person to seek professional help or even to go to the hospital for treatment of injuries. She might even hide it from her family/ friends, especially because they will encourage her to leave her abuser. Kearney (2001) holds the view that abused women hide violent attacks to chidren, family, friends, neighbours and strangers to avoid outside interference and retaliation from the abuser.

During this stage the abuser takes advantage of the situation and the abusive episodes escalate and become worse. The beating of the victim might even prove fatal. During this stage the woman needs serious support from friends or from the relevant social network that she has, such as the religious leader/traditional leader/community who could be in a position to assist her as she seeks help.

\section{Anger and Retaliation}

This stage occurs when the victim reflects on the abusive experiences that she has gone through and the thought of all this makes her feel angry. During this time the victim realizes that she does not deserve to be treated this way. During the tension-building stage she also gets easily irritated, for she now anticipates whatever violent episode that is likely to flare up. During this stage the woman retaliates and is prepared to fight. Some participants expressed anger as follows:

"I wish I could kill him before he kills me."

Sometimes the victim asks herself the following questions:

What have I done to deserve this?

Why is he doing this to me?

It is interesting that $A$ wife's response to abuse (2001) indicates that unresolved, vindictive anger gradually turns the victim into a hard woman. She develops an "I don't care" attitude, starts living a reckless life and seeks comfort by falling in love with other men.” An angry person becomes vulnerable to any situation. She may also want to return evil for evil. As violence breeds violence the victim may ultimately become very violent. If this stage continues for a long period it leads to "spiritual dearth" where a victim no longer cares about her morality. She may start seeking comfort from other men and start having extramarital affairs. Some women start abusing alcohol as a way of dealing with the problem. During this stage a victim may resort to negative strategies as a way of dealing with abusive episodes.
Two of the families that were experiencing violence in the home have children as a result of extramarital affairs and their husbands knew about those incidences. One of them said: "I did not plan to have this child but I found myself sleeping with another man who loved me and could listen to me as I told him all my problems."

Another one said: It was an unplanned pregnancy I was no longer on contraceptives because he hardly had sex with me, but this other man was very protective of me, I do not know how it happened."

The victim may be very dangerous, as she is now prepared for war as a way of self-defence and she may accidentally kill the husband. A National Family Violence Survey conducted by Sniechowski and Sherven (2002) reports that women use weapons to make up for their physical disadvantage as a way of self-defense. A study conducted by Straus and Gelles (1996) found that most of the violence women commit against their husbands or partners is in self-defense or retaliation.

Walker (in Bohn 1990: 93) indicates that the victim must replace self-blame and depression with anger as this will help her to view her relationship realistically. This will encourage her to leave the perpetrator, thus she enters into the self-discovery stage.

\section{Self-discovery}

During this stage the victim is coming to terms with reality. She now takes stock of losses and gains and began a search for meaning and a new understanding of their authentic self (Kearney 2001). She now realizes that she should stop blaming herself for the abuse as she is not responsible for the abuser to change his behaviour. It is up to him. During this stage she makes the decision to leave the abusive relationship.

Some women expressed their views as to how they came to terms with their abusive relationships as follows:"My kids need me, so I should save them from this animal."

"It is not my fault that I am abused."

When the victim is going through this stage she becomes aware of who she is and what she really wants in her life.

This is a very dangerous stage in an abusive relationship because the abuser is not prepared to accept the divorce (Taylor and Francis 2000). This makes him feel worthless and his control is taken 
away. This is supported by literature Hawthorne (1994) states that most women are killed when they are trying to leave their abusers.

If a woman leaves an abusive relationship before she is ready to rediscover who she is, she will go back to the abuser. Leaving an abusive relationship is a process which needs resources and support from family, friends and other women who have gone through the same situation. White (1995) indicates that it takes years of suffering before a woman finally gets enough confidence, courage and gumption to leave her abuser. Therefore it takes combined efforts of friends, family counselors and support groups to help her end the violence.

All victims of domestic violence experience these stages differently, depending on their unique situations. Prolonged interaction with the victims allows one to understand their situation. Thus, for the victims to succeed in dealing with the perpetrators, they need continual support from people who understand their situation and who will not judge them.

They need to be assured that there is nothing they can do. It is up to the perpetrator to deal with his own inadequacies (Laserkohn in SABC 2002). If leaving her husband is the only solution the woman should be prepared to go through the abovementioned stages so that she will be able to cope with the situation.

Victims of domestic violence, therefore, cannot manage their situation on their own. The community needs to stop victim-blaming and focus on encouraging them to reach a stage of selfdiscovery before they are killed.

\section{CONCLUSION}

Whereas domestic violence has been declared a public health problem, it is imperative that the scope of intervention should not only be grounded on public institutions but also hinge on societal networks that can be leveraged beyond the referral function. If health practitioners are ever to demonstrate their seriousness about their role in addressing the problem, an acute awareness of the nature of domestic violence as described in Walker's Cycle Theory of Violence is as vital as redirecting the victim's coping mechanisms towards multi-sectoral remedial pathways. Accordingly, this paper goes beyond a run-of-the-mill description of what has become a public health problem and proposes a set of empowerment programmes that better enable the victim's access to and leverage of intervention structures to which they are referred. This is critical to the extent that holistic approaches ring hollow, however well-intentioned, if the victims are not adequately prepared with respect to soliciting proper assistance at appropriate stages until they are able to be a self-dependent resource to themselves and others in similar situations.

\section{RECOMMENDATIONS}

In some instances victims did not know what to do when they are abused. The perpetrators took advantage of the situation as they advise the victims that they should not talk about their family affairs with other people.

Rigorous training regarding the following is essential:

- Women should be encouraged to report the perpetrators immediately. They should not wait until the problem is unbearable because perpetrators then get used to abusing their partners. If women do not report them immediately they usually resort to abusing their partners as a mechanism of resolving conflict.

- Understanding the cycle of domestic violence that traps women in abusive relationships. Victims need information regarding the cycle and the stages of domestic violence as this could help them to understand why they behave the way they do. It is hoped that this information would assist them to speak out immediately and seek help for their children as well as their abusive partners before they get used to abuse as a life style.

- Cultural beliefs about gender and sex roles.

- Empowerment programmes for women to enhance life skills such as:

- dealing with gender based violence and steps to be taken when faced with domestic violence; breaking the silence and safety tips;

- building the self-concept;

- self-development projects to encourage financial independence;

- workshops on assertiveness;

- workshops on effective communication;

- workshops on reproductive health and gender related issues;

- the Domestic Violence Act (Act no 116 of 1998);

- the Maintenance Act (Act no 99 of 1996); 


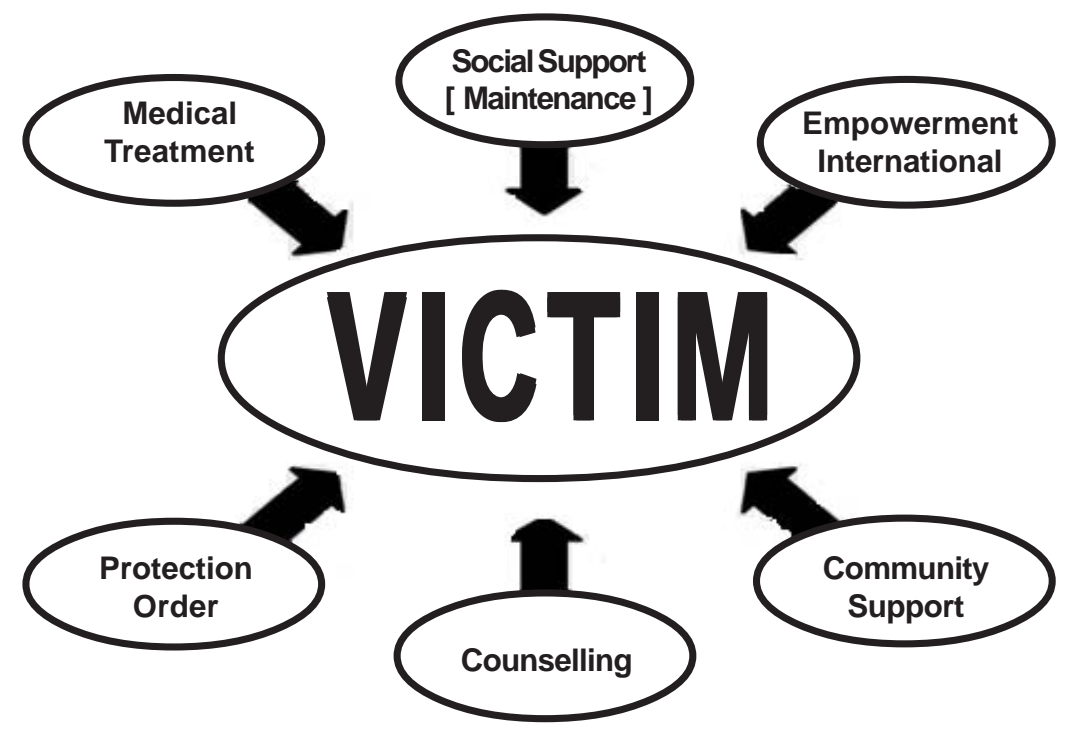

Fig. 1. Services recommended for a physically assaulted victim

- the Human Rights Constitution Act (Act no 108 of 1996). No one has the right to abuse the other. Therefore abuse is a crime;

- formation of support groups of women to fight against domestic violence;

- life as a survivor of domestic violence;

- sharing lived experiences of domestic violence as part of therapy.

The support provided for the victims of domestic violence should be holistic. That is to say that when the victim arrives at an emergency service she should also be provided with all other services whilst receiving medical care, depending on the condition. Counselling of the victims is important to deal with emotional trauma. The police on the other hand should be available to encourage the victim to apply for a protection order. Referrals should be made depending on the needs of the victim. The victims should be provided with legal support so that they are prepared for court proceedings. Workshops are conducted after discharge so as to provide continual support to the victims of domestic violence.

The diagram that follows (Fig.1) gives an explanation on the support provided for the victims of domestic violence. The diagram summarises holistic support necessary for women exposed to domestic violence.

\section{REFERENCES}

A Wife's response to abuse. 2001. Why does an abused wife respond the way she does? From http:// www.gospelcom.net/rbc/ds/cb951/point1.html (Retrieved May16, 2009)

Author N 2000. Women: An endangered species. Health Care for Women International, 21(3): 137-138.

Bessett A, Fishburne L 1995. Television show. What's love got to do with it. Tina Turner's Biography.

Birken RA 2002. Prone to abuse. Payne communications and the Texas network. Your Family's Health. Retrieved May 03, 2009. From http://www. your familyshealth.com/community health/domestic/ (Retrieved May 03, 2009).

Bochonok S 2000. Domestic violence sermon: Be safe and well. Peace Joy Courage. From http//www. soulfoodministry.org/docs/English/Domestic Violence.htm (Retrieved October 17, 2009).

Bohn DK 1990. Domestic violence and pregnancy. Implications for practice. Journal of NurseMidwifery, 35(2): 86-97.

Crawford C 2001. No safe place: Violence against women. From http://www.pbs.org/kued/nosafeplace/studyg/ domestic.html (Retrieved October 17, 2009).

Democratic Nurses Organization of South Africa 1998. Ethical Standards for Nurse Researchers. DENOSA: Pretoria.

Ferraro K, Johnson J 1983. How women experience battering: The process of victimization. Social Problems, 30: 325-339.

Gerhard M 2000. Domestic Violence. Family violence: Conjugal Violence, 63(12): 52-58.

Hawthorne T 1994. Programs for batterers see success only for the motivated few. Psychotherapy Letter, 6(7): $12-16$. 
Kearney MH 2001. Enduring Love: A Grounded Formal Theory of Women's Experienceof Domestic Violence. Research in Nursing \& Health, 24: 270-282.

Kvale S 1983. The qualitative interview, a phenomeno-logical and a hermeneutical mode of understanding. Journal of Phenomenological Psychology, 14: 171-196.

Lempert L 1996. Women's strategies for survival: Developing agency in abusive relationships. Journal of Family Relations, 11: 269-289.

Lincoln YS, Guba EG 1985. Naturalistic Enquiry. London: Sage.

Vetcamp, LJ Miller, TW 1990. Clinical Strategies in Recognizing spouse abuse. Psychiatry Quarterly, 61(3): 179-187.

National Center for Injury Prevention and Control. 2003. Costs of Intimate Partner Violence against Women in the United States. Atlanta GA: Centre for Disease Control

Olson LN 2002. Exploring common couple violence in heterosexual romantic relationships. Western Journal of Communication, 66(1): 104-128.

Peterson C, Maier SF, Seligman MEP 1993. Learned Helplessness. A theory for the Age of Personal Control. New York: Oxford University.

Pierson J 2001. Abusive relationships. From http:// www.bu.edu/counselling/abuserela.htm (Retrieved June 04, 2008).

Pilowsky J 1993. The Price of a Wife is Thirteen Cents: An Exploration of Abused Spanish-Speaking Women. Unpublished dissertation.Toronto, Ontari: University of Toronto.
SABC 2007. Till death do us part. Special Assignment Video:August $27^{\text {th }}$ 2002. Auckland Park, Johannesburg. Sniechowski J, Sherven J 2002. Blaming men doesn’t stop domestic violence. American Fathers' Coalition. From http://www.vix.com/men/battery/commentary/ sniechowski.html (Retrieved October 22, 2008).

Straus MA, Gelles RJ 1996. Physical Violence in American Families. New Brunswick: Transaction.

South Africa 1998. Domestic violence Act 116 of 1998. Pretoria: Government

South Africa 1996. Maintenance Act 99 of 1996. Pretoria: Government.

South Africa 1996. The Republic of South Africa Constitution Act 108 of 1996. Pretoria: Government

Taylor Francis 2000. Women: An endangered species. Health Care for Women International, 21: 137-138.

The Women's Rural Advisory Programs 1996. A survivor tells her story. Let's WRAP. From http://www. lets wrap.com/survivor/surv2.htm (Retrieved February 15, 2010).

Walker LE 1984. The Battered Woman Syndrome. United States of America: Springer.

White N 1995. Batterers seldom stop after the first time. Domestic Violence. From http://www.s-tcom/projects/ DomVio/battersseldom.HTML(Retrieved November 12, 2009).

World Health Organization (WHO) 2003. Gender dimension of HIV status disclosure to sexual partners: Rates, barriers and outcomes. Review Paper. Geneva: WHO. 